\title{
Téoros
}

Revue de recherche en tourisme

\section{Bibliographie. Les Laurentides}

\section{Valérie Théberge}

Volume 15, numéro 1, printemps 1996

Les Laurentides, quelles Laurentides?

URI : https://id.erudit.org/iderudit/1075054ar

DOI : https://doi.org/10.7202/1075054ar

Aller au sommaire du numéro

Éditeur(s)

Université du Québec à Montréal

ISSN

0712-8657 (imprimé)

1923-2705 (numérique)

Découvrir la revue

Citer ce document

Théberge, V. (1996). Bibliographie. Les Laurentides. Téoros, 15(1), 43-43.

https://doi.org/10.7202/1075054ar d'utilisation que vous pouvez consulter en ligne.

https://apropos.erudit.org/fr/usagers/politique-dutilisation/ 


\section{Bibliographie \\ Les Laurentides}

Association touristique des Laurentides, Pare linéalre quatre salsons des Laurentides: présentalion du prolet, devls d'étude et plan de travall. Saint-Jérôme: Association tourlstique des laurentudes, 1989, S.P.

Assoclation tourlstlque des Laurentides, Plan de développement tourlstlque des Laurentides phase IV: portralt de la demande et caracteristique des marches des voyageurs d'agrément, vlsiteurs et non-vlsileurs des Laurentides. Salnt-Jéröme: Assoclation touristique des Laurentides. 1987, S.P.

Association touristique des Laurentides el CEGIR. Plan de developpement Louristique des LawrenLdes: rapport Anal. Saint-Jérôme: Assoclation touristique des Laurentides, 1987, 129 pages.

Assoclation Louristique des Laurentides et CEGIR. Plan de développement tourlsuque des Laurentides: sommarre exécullf. Salnt-Jérôme: Association touristique des Laurentides, 1987, 60 pages.

Assoclation tourlstique des Laurentides. Plan de dóveloppement touristique phase IV: caracteristiques des marchés (1er sondage). Saint-Jerrome: Assoclation touristlque des Laurentides, 1986, S.P.

Brodeur, Claudette. La station Mont-Tremblant. Montréal: Chatre en tourisme, 1993, 33 pages.

CEGIR. Plan de développement touristique phase IV: Ies skleurs: comportements de voyage et destinations Laurent/des, Salnt-Jérôme: Assoclation touristlque des Laurentides, 1986, 137 pages.

Consell de la culture des Laurenudes. Le chemin des selgneurles. Saint-Jérôme: Consell de la culture des Laurentides, 1992, 62 pages.

Consell de la culture des Laurentides. La reglon des Laurentudes et la polltique culurelle. Salnt-Jéròme: Consell de la culture des Laurentides, 1991, 21 pages.

Consell réglonal des lolsirs des Laurentides. Parc du p'u traln du Nord: rapport dos operations hwornalos 1994 1995 du skl de fond. Sant-Jerome / Val-Davld SaintJérôme: Conseil régional des dolsirs des Laurentides. 1995. 37 pages.

Couture, Maurice, Brigilte Folsy et Lise Wiriot. Sommet sur I'avenlr de la destinatlon Mont-Tremblant. S.L.: CADC Laurentides, 1991, 27 pages.
Dlon, Yves. Multipllcateur économlque réglonal pour la réglon adm Inistrative Laurentides-Lanaudlère, réglon 06. Ouébec: Ministere du Loisir. de la Chasse et de la Péche. 1988, 91 pages.

Dugas, Renaud, Mirellle Barrière et Romuald Asselln. Portralt statistique réglonal: réglon de LaurentidesLanaudière et munlclpalités réglonales de comlé. Ouébec: Bureau de la statistique du Québec. 1987, 744 pages.

Dumals, Plerre. Une memore pour l'avenlr: lanchcologle et Ia M.R.C. d'Antolne Labelle. Mont-Laurler: M.R.C. d'Antoine Labelle, 1991. 15 pages.

Groupe Inter-Tech. Evaluatlon du potentel de développement du prodult comblnd skJ Mont-Tremblant/selour à Montréal pour les réglons métropolltalnes amérlcalnes d'Allanta en Georgle el de Maml-Tampa en Florlde: rapport frnal. S.L.: Groupe Inter-Tech, 1994, 28 pages.

Lamothe, Claude, Maurice Couture. 1891-1991: du chem m de fer au parc hncalre des Laurentides, S.L.: Corporation de dóveloppement des Laurentides, 1991, 16 pages.

Lévesque, Gllbert et Christlan Vachon. La M.R.C. des Laurentides: la richesse d'un patrimolne. Salnt-Faustin: Municipalité réglonale de comté des Laurentides, 1990 . 24 pages.

M.R.C. d'Antoine Labelle. Sommet soclo-economique dans la M.R.C. d'Antolne Labelle. Mont-Laurier: M.R.C. d'Antolne Labelle, 1992, 128 pages.

Sotar. Plan directeur de développement ot d'aménagement du Parc Mnéalre des Laurentides: rapport fnnal. Laval: Sotar, 1990.2 volumes.

Sotar. Station tourlstique du Mont-Tremblant: plan directeur de développement el daménagement. Laval: Sotar, 1986. 111 pages.

Zaurrinl, Gabrlel et Julle Raymond. Analyse économ/que des imeslissements du Groupe Intrawest. S.L.: S.N.. 1992, 24 pages.

Cette bibliographie a été préparć par Mme Valérle Théberge du Centre de documentation touristique (ACTA-OQÉBEC) 